\title{
INTRODUCTION
}

\section{Respiratory somnology: a clinical update}

\author{
G.M. Verleden*, B. Buyse*, D. Pevernagie ${ }^{\#}$ and M. Demedts*
}

D uring recent years, it has become evident that disturbed sleep, whether central sleep apnoea syndrome or obstructive sleep-disordered breathing (SDB), may lead to several other effects, such as cardiovascular diseases and many metabolic disturbances. Although the treatment of these sleeping problems is based on ventilatory support and pharmacological agents (in the case of central sleep apnoea or hypoventilation), positive airway pressure systems or upper airway surgery/oral appliances (in the case of obstructive SDB), the treatment effects are not always clear. The treatment effects, in particular on metabolic disturbances, need more investigation, whereas some effects, for instance, on cardiovascular outcome parameters, already seem quite convincing. Related ethical dilemmas may also arise, such as "sleep apnoea and driving", where it is not always easy to find the optimal solution.

The purpose of the international symposium "Respiratory somnology: a clinical update", organised by the Dept of Respiratory Diseases of the University Hospital Gasthuisberg at the Katholieke Universiteit, Leuven (Belgium) on March 16-18, 2006, which forms the subject of the current issue of the ERR, was to provide a clinical update of several issues regarding sleep and its related problems. Various clinical and basic researchers and internationally renowned experts in the field were brought together from all over Europe to discuss various topics related to sleep disorders and its possible consequences for health.

In the first article, Pevernagie et al. [1] discuss the role of ventilatory support (nasal continuous positive airway pressure (CPAP), bi-level pressure support or adaptive servo-ventilation) and pharmacological treatment, including optimising cardiac condition, theophylline, acetazolamide and/or oxygen, in patients with central apnoea or hypoventilation. In the second article, Pevernagie et al. [2] deal with the application of stable CPAP via the nose (nasal CPAP), as it has been the mainstay of treatment for more than two decades in obstructive sleep apnoea patients. As there is poor treatment compliance and/or refusal in a large proportion of CPAP-treated patients, BOUDEWYNS et al. [3], in the third article, describe the selection of patients for the different conservative (oral appliances) and surgical treatment modalities (upper airway surgery by soft tissue resection (uvulopalatopharyngoplasty, etc.) and skeletal procedures, such as maxillo-mandibular advancement).

BUYSE et al. [4] discuss the effect of CPAP on different outcome parameters, such as sleepiness and attention deficits, as well as higher cognitive/executive defects in obstructive sleep apnoea syndrome (OSAS), whereas the subsequent paper by BUYSE et al. [5] explores the relationship between obstructive sleep apnoea and hypertension and arterial vascular diseases, such as stroke and ischaemic coronary disease. JAHAVERI [6] discusses the role of sleep apnoea and hypopnoea as potential contributing factors in the progressively declining course of left and right ventricular remodelling and dysfunction in heart failure. Excessive daytime sleepiness with obstructive sleep apnoea is one of the most prevalent causes, and is associated with an increased risk of traffic accidents. KRIEGER [7] extensively discusses how this ethical dilemma should be dealt with.

In the penultimate article, HARSCH [8] discusses the metabolic disturbances in patients with OSAS, such as insulin resistance, elevated proinflammatory cytokines and vascular adhesion molecules, as well as an elevation of hormones derived from the adipose tissue, such as leptin. Although sleep apnoea syndrome is associated with cardiovascular morbidity, it is less clear if it is also associated with increased mortality. In the final article, LAVIE [9] reviews the data supporting an increased risk of mortality in patients with severe sleep apnoea in comparison with individuals with mild or no sleep apnoea, and the evidence for efficient treatment in decreasing mortality.

It is very much hoped that this issue of the European Respiratory Review will provide an interesting synthesis and update of the current knowledge of respiratory somnology.

\section{ACKNOWLEDGEMENTS}

The authors are very grateful to P.S. Burge, Editor-in-Chief, for granting them the privilege of publishing the international symposium
AFFILIATIONS

*Dept of Respiratory Diseases, University Hospital Gasthuisberg, Leuven, and

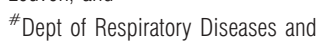
Sleep Medicine Centre, Ghent University Hospital Ghent, Belgium.

\section{CORRESPONDENCE}

G.M. Verleden

Dept of Respiratory Diseases

University Hospital Gasthuisberg

49, Herestraat

B-3000 Leuven

Belgium

Fax: 3216346803

E-mail: geert.verleden@

uz.kuleuven.ac.be

\section{STATEMENT OF INTEREST}

The symposium presented in the current issue of the European Respiratory Review (ERR) was sponsored by GlaxoSmithKline (GSK), Belgium, in the framework of the "GSK Chair in Respiratory Pharmacology at the Katholieke Universiteit, Leuven", attributed to G.M. Verleden.

M. Demedts received consulting fees from Zambon, Wyeth, Roche, Boehringer-Ingelheim and Intermune; and lecture fees from GlaxoSmithKline, AstraZeneca and Zambon. 
"Respiratory somnology: a clinical update" in the European Respiratory Review.

\section{REFERENCES}

1 Pevernagie D, Janssens JP, De Backer W, Elliott M, Pepperell J, Andreas S. Ventilatory support and pharmacological treatment of patients with central apnoea or hypoventilation during sleep. Eur Respir Rev 2007; 16: 115-124.

2 Pevernagie D, Masa JF, Meurice JC, Farré R, Marrone O, Rodenstein D. Treatment of obstructive sleep-disordered breathing with positive airway pressure systems. Eur Respir Rev 2007; 16: 125-131.

3 Boudewyns A, Marklund M, Hochban W. Alternatives for OSAHS treatment: selection of patients for upper airway surgery and oral appliances. Eur Respir Rev 2007; 16: 132-145.
4 Buyse B, the participants of working group 2. Treatment effects of sleep apnoea: where are we now? Eur Respir Rev 2007; 16: 146-168.

5 Buyse B, Hedner J, the participants of working group 2. Sleep apnoea, hypertension and vascular disease: where are we now? Eur Respir Rev 2007; 16: 169-182.

6 Javaheri S. Treatment of obstructive and central sleep apnoea in heart failure: practical options. Eur Respir Rev 2007; 16: 183-188.

7 Krieger J. Sleep apnoea and driving: how can this be dealt with? Eur Respir Rev 2007; 16: 189-195.

8 Harsch IA. Metabolic disturbances in patients with obstructive sleep apnoea syndrome. Eur Respir Rev 2007; 16: 196202.

9 Lavie P. Mortality in sleep apnoea syndrome: a review of the evidence. Eur Respir Rev 2007; 16: 203-210. 